\title{
Formaldehyde degradation by a newly isolated fungus Aspergillus sp. HUA
}

\author{
D. S. Yu • G. Song $\cdot$ L. L. Song $\cdot$ W. Wang $\cdot$ \\ C. H. Guo
}

Received: 8 September 2013/Accepted: 3 November 2013/Published online: 27 November 2013

(C) Islamic Azad University (IAU) 2013

\begin{abstract}
Formaldehyde is widely used in chemical manufacturing industry and classified as a human carcinogen. Discharging wastewater containing formaldehyde without treatment can cause serious risk to the water environment. In this study, a formaldehyde-resistant fungal strain was isolated from sewerage of a furniture factory. Isolate strain was identified based on the morphological and phylogenetic analyses. Formaldehyde-degrading fungus was determined by characterizing the mycelia growth in culture media, formaldehyde-resistant, formaldehydedegrading efficiencies, and specific enzyme activity involved in formaldehyde removal. Isolate strain HUA was identified as a member of Aspergillus sydowii. The strain HUA showed a growth in the presence of formaldehyde up to $2,400 \mathrm{mg} \mathrm{l}^{-1}$ at an optimum temperature of $25^{\circ} \mathrm{C}$ and optimum $\mathrm{pH}$ of 7 . The specific activity of formaldehyde dehydrogenase and formate dehydrogenase could reach up to 5.02 and $1.06 \mathrm{U} \mathrm{mg}^{-1}$, respectively. It indicated that isolated formaldehyde-resistant A. sydowii HUA strain would be potential used for removing formaldehyde from industrial wastewater.
\end{abstract}

Keywords Biodegradation - Formaldehyde . Formaldehyde-degrading fungus $\cdot$ Aspergillus sydowii . Wastewater

D. S. Yu · G. Song · L. L. Song · W. Wang · C. H. Guo (ه) Key Laboratory of Molecular and Cytogenetics, Heilongjiang Province, College of Life Science and Technology, Harbin Normal University, Harbin 150025, China e-mail: kaku_2008@163.com

\section{Introduction}

Formaldehyde, a highly reactive chemical material, is widely used in chemical manufacturing industry. It is often released from wastewater of construction, textile, wood processing, furniture, and pharmacy industry (Tang et al. 2009). Formaldehyde is a water-soluble compound, which can diffuse into many tissues rapidly, react with different macromolecules such as proteins and nucleic acids, cause DNA-DNA, protein-DNA, and protein-protein cross-links (Metz et al. 2004; Merk and Speit 1998; Solomon and Varshavsky 1985). Therefore, it has a toxic effect on all organisms, the IARC (2006) (International Agency for Research on Cancer) has classified formaldehyde as a human carcinogen that causes nasopharyngeal cancer and probably leukemia.

Discharging wastewater containing formaldehyde generated by organic synthesis cause environmental worsening and human disease (Tišler and Zagorc-Koncan 1997). Much more researches have been done to wastewater treatment (Moussavi and Heidarizad 2010). Biological control, such as microbial degradation, is the most commonly applied method for treatment of wastewaters containing biodegradable compounds (Bhakta et al. 2012; Kanmani et al. 2012; Ashraf et al. 2011). Many microorganisms have been shown to degrade formaldehyde in the sewage, and bacterial degradability has been the research hotspot on formaldehyde degradation (Di Maiuta et al. 2009; Arutchelvan et al. 2005; Hidalgo et al. 2002). Nevertheless, there is fewer fungal resources that are able to degrade formaldehyde have been reported (Sawada et al. 2006). Filamentous fungus plays an important role in bioremediation in wastewater treatment (Mani and Kumar 2013; Usharani and Muthukumar 2013; More et al. 2010). It is shown that filamentous fungus A. versicolor and $A$. 
niger has bio-accumulate capacity of heavy metal from industrial effluent (Taştan et al. 2010; Das et al. 2007; Srivastava and Thakur 2006). The effects of biodegrading behavior of polymers and utilization of organophosphate pesticides by genus Aspergillus have been reported (Zhao et al. 2005).

Formaldehyde presents as a natural product endogenous biological compound in most living systems (Tang et al. 2009). Formaldehyde is situated at the branch point between dissimilation and assimilation pathway of formaldehyde (Yurimoto et al. 2005). Organisms have several biological forms of formaldehyde metabolism to deal with the hazards of formaldehyde. One of which is the combination of formaldehyde with cofactors, the combination product then is oxidized into $\mathrm{CO}_{2}$ and generated energy (Hanson and Roje 2001). The glutathione (GSH)-dependent formaldehyde dehydrogenase (FADH) and formate dehydrogenase $(\mathrm{FDH})$ participate in the above strategy (Tada and Kidu 2011). In addition, formaldehyde participate the $\mathrm{C}_{1}$ assimilation pathways, the xylulose monophosphate pathway in yeasts, and the ribulose monophosphate pathway in methylotrophic bacteria (Yurimoto et al. 2009).

There are few reports on fungal degradation of formaldehyde and filamentous fungi formaldehyde metabolism. The aims of this study were to isolate and identify formaldehyde-degrading fungi and to determine the effects of the degradation of formaldehyde and the activities of key enzymes in formaldehyde metabolism.

\section{Materials and methods}

Fungal isolation and cultivation

The sludge samples were collected from sewerage of a furniture factory (Harbin, China). The samples were stored at $4{ }^{\circ} \mathrm{C}$ in sterile plastic bags. The sludge $(10 \mathrm{~g})$ was transferred into $90 \mathrm{ml}$ of the sterilized liquid basal medium (1 l) contained: sucrose $3 \% ; \mathrm{NaNO}_{3} 0.3 \% ; \mathrm{K}_{2} \mathrm{HPO}_{4}$ $0.1 \% ; \mathrm{MgSO}_{4} \cdot 7 \mathrm{H}_{2} \mathrm{O} 0.05 \% ; \mathrm{KCl} 0.05 \% ; \mathrm{FeSO}_{4} \cdot 7 \mathrm{H}_{2} \mathrm{O}$ $0.001 \%$ (adjusted to $\mathrm{pH} 7$ ) supplemented with $150 \mathrm{mg}$ formaldehyde and incubated at $30{ }^{\circ} \mathrm{C}$ shaking with $180 \mathrm{rpm}$. After cultivation for 5 days, the culture was inoculated to plates containing basal medium with $2 \%$ agar and $150 \mathrm{mg} \mathrm{l}^{-1}$ formaldehyde incubated at $30{ }^{\circ} \mathrm{C}$. Single colony was picked up and inoculated into another new plate. Above operation was repeated several times until the pure cultures were obtained.

Identification and characterization of isolates

The fungal isolates were incubated on basal medium agar plates in the dark at $25{ }^{\circ} \mathrm{C}$ for 15 days. At the end of the cultivation, morphology (colony growth, color of conidia, mycelia, exudate, and colony reverse) was characterized using light microscope (Leica DM1000, Leica Microsystems Germany). The genomic DNA was obtained from the mycelia according to the method of Zhang et al. (1996). Partial fragments of ITS region (internal transcribed spacer region of the ribosomal DNA containing ITS1, ITS2, and 5.8S rRNA gene) and $\beta$-tubulin gene of strain HUA were amplified for sequence analysis. The primers and conditions used to amplify the ITS region and the $\beta$-tubulin gene have been described previously (Glass and Donaldson 1995). The $\beta$-tubulin gene was sequenced to help clarify interspecific relationships when ITS region was inadequate for definitive identification. The amplified products were sequenced at Sangon Biotech (Shanghai, China). Alignment of the determined sequences and those of related ITS regions and $\beta$-tubulin sequences from the GenBank database by searching with BLAST program was aligned using ClustalX with manual adjustment (Thompson et al. 1997). Phylogenesis analysis was performed with MEGA4, and the evolutionary distances between the sequences were calculated using Kimura's two-parameter model (Tamura et al. 2007). The phylogenetic trees were constructed by the neighbor-joining method with bootstrap analysis (Saitou and Nei 1987).

The optimal temperature for isolates growth was determined by measuring the dry cell mass of mycelia under different temperatures. Flasks containing $100 \mathrm{ml}$ of liquid basal medium inoculated with almost $10 \mathrm{mg}$ (fresh weight) mycelia, which previously cultured aerobically in $100 \mathrm{ml}$ basal medium on a shaker $(180 \mathrm{rpm})$ at $30^{\circ} \mathrm{C}$ for 5 days. The isolates were incubated at $20,25,30,35$, and $40{ }^{\circ} \mathrm{C}$, the cultivation was carried out with shaking at $180 \mathrm{rpm}$ for 7 days to investigate temperature profile. Mycelia were collected by filtration through filters and measured after drying to a constant weight at $105{ }^{\circ} \mathrm{C}$.

\section{Formaldehyde resistance and degradation}

Formaldehyde resistance and biodegradation of isolates with different initial formaldehyde concentrations were screened in liquid medium. Pre-culture of isolates, as described for characterization above, was inoculated in basal medium (50 ml) supplemented with $600-2,400 \mathrm{mg} \mathrm{l}^{-1}$ of formaldehyde. In order to clarify the connection between formaldehyde degradation curve and fungal growth, fungal initial inoculation amount control in this experiment was $10 \mathrm{mg}$ of fresh weight. Control of formaldehyde solution with same amount of the autoclaved mycelia was run in parallel. All cultivations were repeated five times. The flasks were incubated at $25{ }^{\circ} \mathrm{C}$ with shaking at $180 \mathrm{rpm}$ for 7 days. The residual formaldehyde was determined as previous description (Nash 1953). Growth rates were determined by 
measuring the fresh weight in time course. The experiments were performed in three replications.

The characterization of formaldehyde degradation

To characterize the formaldehyde degradation under aerobic condition efficiency of fungal strains, the effects of initial $\mathrm{pH}$ and supplemental carbon sources were investigated. The pre-culture $(10 \mathrm{mg})$ of fungal strains was inoculated in autoclaved liquid basal medium supplemented with $1,500 \mathrm{mg} \mathrm{l}^{-1}$ formaldehyde. The $\mathrm{pH}$ of medium was adjusted from $\mathrm{pH} 4$ to $\mathrm{pH}$ 8. Mycelia were collected as describe above after incubation at $25^{\circ} \mathrm{C}$ for 7 days. Formaldehyde-degrading abilities of the isolates under different carbon conditions were characterized by 4 different carbon media supplemented with $1,500 \mathrm{mg} \mathrm{l}^{-1}$ formaldehyde. Different carbon media were set by adding (w/v) $3 \%$ glucose, $3 \%$ lactose, and $3 \%$ soluble starch replaced $3 \%$ sucrose in basal medium. Basal medium with same amount of the autoclaved cells was set as control. In addition, basal medium without carbon source addition to
$1,500 \mathrm{mg} \mathrm{l}^{-1}$ formaldehyde was set to detect formaldehyde degradation ability of HUA-utilizing formaldehyde as the sole carbon source. All cultivations were repeated five times. Cultivation was carried out with shaking at $180 \mathrm{rpm}$ at $25{ }^{\circ} \mathrm{C}$ for 7 days. Formaldehyde concentration was analyzed with methods descript before. Fresh weight of mycelia and residual formaldehyde was measured every day.

\section{Enzyme activity assay}

A basal medium supplemented with $300 \mathrm{mg}^{-1}$ formaldehyde was set as enzyme-inducing medium, and a basal medium without formaldehyde was used as the control. Mycelia were then collected by filtration and washed well with sodium phosphate buffer ( $\mathrm{pH}$ 7.5). Crude enzyme extract was obtained through sonication $(4 \mathrm{~V}, 50 \mathrm{~Hz})$ at $4{ }^{\circ} \mathrm{C}$ for $30 \mathrm{~s}$ and centrifuged $13,000 \mathrm{rpm}$ for $10 \mathrm{~min}$. Enzyme activities of GSH-dependent FADH and FDH were assayed at $340 \mathrm{~nm}$ spectrophotometrically by monitoring the formation of NADH using a photometer (Hitachi
Fig. 1 Characterization of HUA: a fungal colony grown on basal medium agar,

b conidiogenous structures, c neighbor-joining phylogenetic tree based on $\beta$-tubulin sequences of HUA and other related taxa

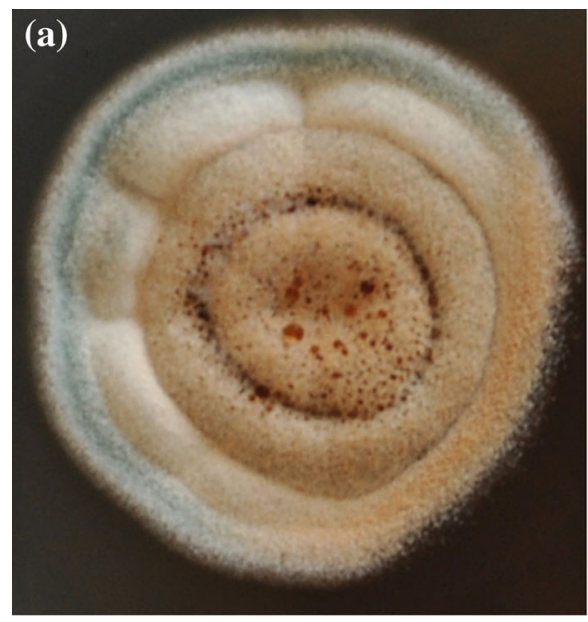

(b)

(c)

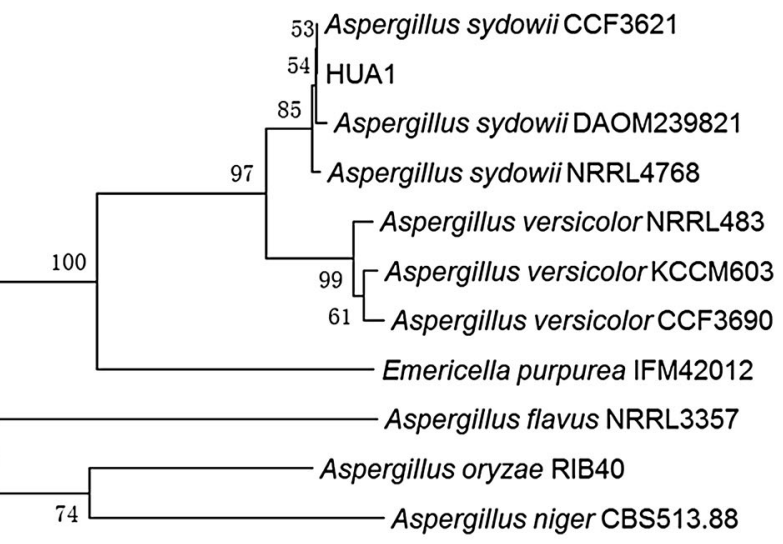

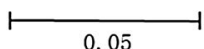



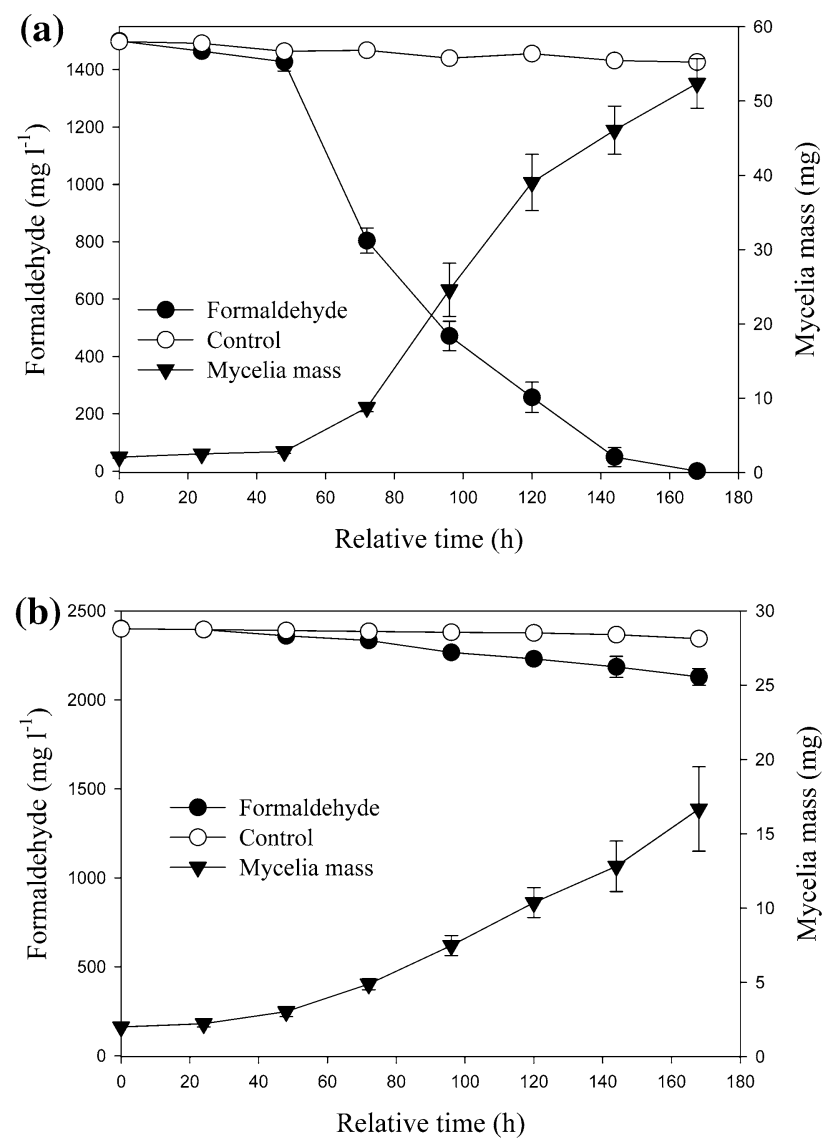

Fig. 2 Formaldehyde degradation of HUA with different initial formaldehyde concentration: $\mathbf{a} 1,500 \mathrm{mg}^{-1}$ and $\mathbf{b}, 2,400 \mathrm{mg}^{-1}$

U-2800, Japan) (Schutte et al. 1976). The protein concentration of crude enzyme extracts was estimated according to Bradford method (1976).

\section{Statistical analysis}

Statistical analysis was performed using SPSS for Windows version 16.0 (SPSS Inc., USA) and Excel (Microsoft, USA). Graphical representations were presented using Sigma Plot for Windows version 11.0 (SPSS Inc., USA). Data were statistically evaluated using one-way analysis of variance, and significant differences between means were determined by Duncan's multiple range tests $(p<0.05)$.

\section{Results and discussion}

Identification and characterization of fungal strain HUA

A fungal strain HUA was isolated on basal medium agar plate supplemented with $150 \mathrm{mg}^{-1}$ formaldehyde through a simple procedure. The colony color was white at first and then turned to olive, the reverse color was white initially and then turned to orange (Fig. 1a). The color of exudates and soluble pigments were brown and orange, respectively. Radiation pattern was found on both surface and medium. Sporangium and conidiogenous cells were globose-shaped (Fig. 1b). The ITS region of strain HUA was selected as the specific sequence for phylogenetic analysis. When comparing with public ITS region sequences in the GenBank database, HUA exhibited the highest ITS gene sequence similarity to Aspergillus sydowii (99\%) and Aspergillus versicolor (99\%), both belonged to Aspergillus section versicolors. The $\beta$-tubulin conserved sequence confirmed that strain HUA belonged to A. sydowii (Fig. 1c). Temperature had substantial effect on the dry cell mass of strain HUA. The strain could grow in the range of temperature $20-35^{\circ} \mathrm{C}$, and the optimum temperature for strain was $25^{\circ} \mathrm{C}$, whereas HUA could not grow at $40{ }^{\circ} \mathrm{C}$.

Formaldehyde resistance and degradation in liquid medium

The pre-culture strain HUA could completely degrade formaldehyde with initial concentration of 600, 900, 1,200, and 1,500 $\mathrm{mg}^{-1}$ within 4, 5, 6, 7 days, respectively. With an increase in mycelia mass, the formaldehyde concentration $\left(1,500 \mathrm{mg}^{-1}\right)$ reduced gradually in medium (Fig. 2a). As shown in Fig. 2a, in the first 2 days, the fungal mycelia mass and the concentration of formaldehyde were almost unchanged. However, mycelia mass increased rapidly after the second day. At the same time, the formaldehyde concentration decreased rapidly, the amounts of formaldehyde degraded by the strains HUA per gram of mycelia and per hour was $8.9 \mathrm{mg}$ beyond $6.3 \mathrm{mg}$ as previously reported about a formaldehyde-degrading fungus, Trichoderma virens BDF002 (Sawada et al. 2006). The strain HUA was able to grow in the presence of formaldehyde up to $2,400 \mathrm{mg} \mathrm{l}^{-1}$ (Fig. 2b). Many fungi are resistant to formaldehyde (Kondo et al. 2008, 2002). According to Sawada et al. (2006), Trichoderma virens was identified as formaldehyde-resistant strains based on morphological and phylogenetic analyses.

Effect of initial $\mathrm{pH}$ on formaldehyde degradation

The formaldehyde degradation was dependent upon $\mathrm{pH}$ values. The experiments were performed in the range of $\mathrm{pH}$ 4 to $\mathrm{pH} 8$ for formaldehyde degrading. Formaldehyde removal was $40.04 \%$ at $\mathrm{pH} 4,89.49 \%$ at $\mathrm{pH} 5,82.12 \%$ at pH $6,100 \%$ at pH 7, and $38.96 \%$ at pH 8 after 7 days. It was observed that the biodegrading of formaldehyde 
Fig. 3 Formaldehyde degradation of HUA with initial formaldehyde concentration of $1500 \mathrm{mg}^{-1}$ in different carbon sources: a fungal mass and b formaldehyde degradation

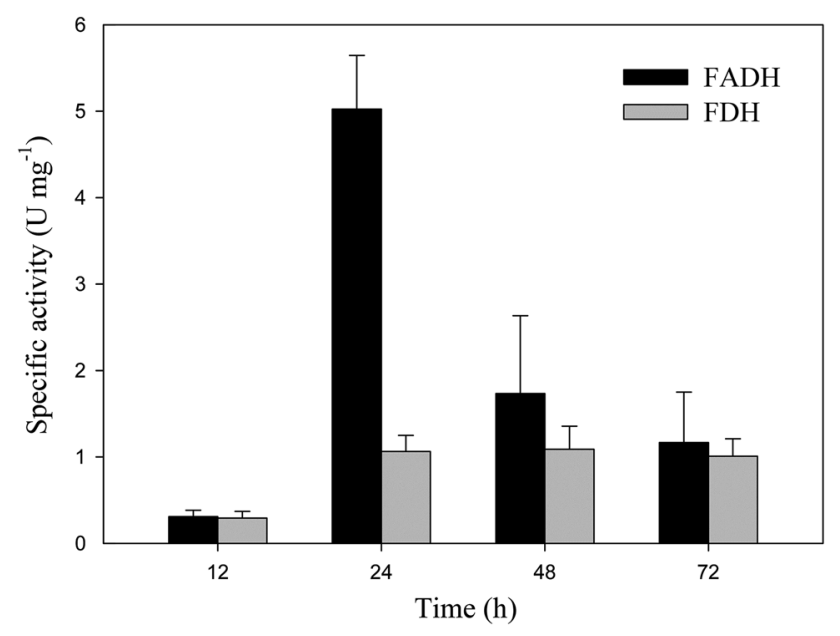

Fig. 4 Enzyme activities of HUA grown on inducing medium supplemented with formaldehyde

increased between $\mathrm{pH}$ ranges from $\mathrm{pH} 5$ to $\mathrm{pH} 7$. Moreover, the mycelia mass also increased between $\mathrm{pH} 5$ and $\mathrm{pH}$ 7. It indicates that fungal mycelia growth state affects
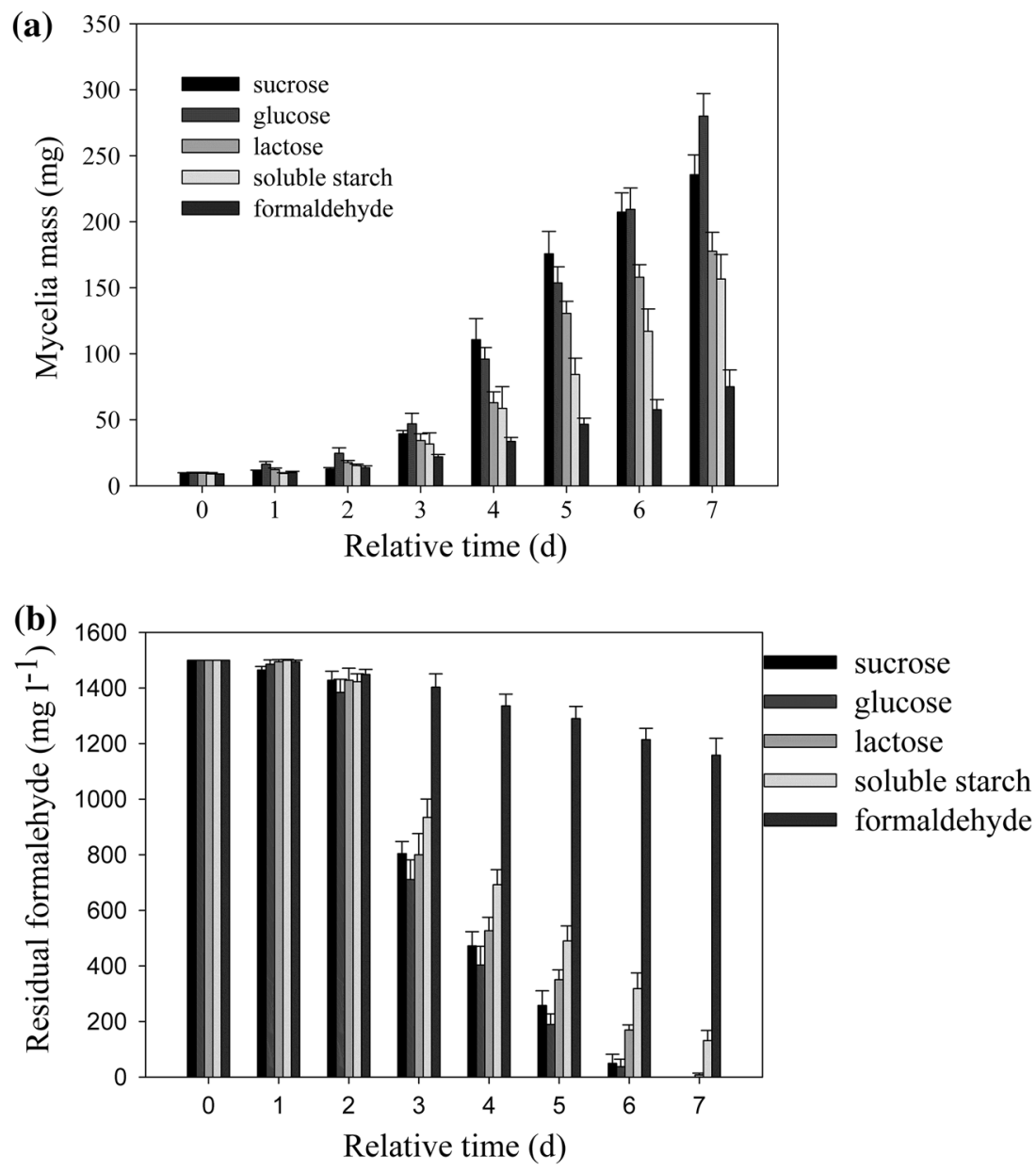

formaldehyde-degrading rates. In the previous paper on the effect of initial $\mathrm{pH}$ on the growth and formaldehydedegrading rates of fungi, it was shown that the formaldehyde-degrading capacity affected by the $\mathrm{pH}$ values of the culture medium, where the optimum $\mathrm{pH}$ values were found to be between 4 and 9 in fungus cultures (Sawada et al. 2006). Fungi within the same genus have similar growth conditions. Similar results were observed, an optimum $\mathrm{pH}$ value range for heavy metal adsorption of fungi belonging to genus Aspergillus has been found from $\mathrm{pH} 5$ to $\mathrm{pH} 7$ (Taştan et al. 2010; Das et al. 2007).

Formaldehyde degradation with different carbon source

Strain HUA could grow in medium with sucrose, glucose, lactose, soluble starch, and formaldehyde as carbon source. These carbon sources had impact on fungal growth. Fresh weight of mycelia grew around the time from 0.01 to $0.24,0.28,0.18,0.16$, and $0.08 \mathrm{~g}$ under the conditions of sucrose, glucose, lactose, soluble starch, and formaldehyde after 7 days (Fig. 3a), respectively. The 
degradation rates of formaldehyde were 100, 100, 99.5, 91.3, and $22.8 \%$ (Fig. 3b), respectively. The amount of evaporation of formaldehyde was $4.8 \%$ in control sample. The result showed strain HUA was able to grow and degrade formaldehyde effective in carbon sources mentioned above.

Aspergillus sydowii spreads widely in ocean water (Martins et al. 2011; Rocha et al. 2010). A. sydowii could be used for field biodegradation of organophosphate pesticides (Hasan 1999). Recent studies have focused on the application of xylanase from A. sydowii (Nair et al. 2008). Closely related fungus $A$. versicolor has been found to play a considerable role in reducing polymer materials and heavy metals such as chromium, copper, and nickel and decolorizing Remazol Blue reactive dye (Taştan et al. 2010). The degradation of formaldehyde by Aspergillus section versicolors has not yet been reported.

\section{Enzyme activity analysis}

Degradation of formaldehyde by strain HUA would occur through the action of FADH and FDH. The activities of FADH and FDH were measured under formaldehydeinduced and non-induced conditions. FADH activity and FDH activity could only be detected under formaldehydeinduced condition. After $12 \mathrm{~h}$ of culturing with formaldehyde, FADH activity can be detected at a lower level that closely resembles FDH (Fig. 4). The activity of FADH reached a maximum after $24 \mathrm{~h}$ induced by formaldehyde, followed by a gradual decrease until to the undetectable levels at the fourth day. FADH activity can reach up to $5.02 \mathrm{U} \mathrm{mg}^{-1}$. After induction of $24 \mathrm{~h}, \mathrm{FDH}$ was possible to achieve the maximum, and after that, the activity was maintained to formaldehyde completely consumed. Activity of FDH achieved the highest $1.06 \mathrm{U} \mathrm{mg}^{-1}$. The activity of formaldehyde dehydrogenase was higher than that of formate dehydrogenase during the entire formaldehyde metabolism.

Formaldehyde degradation pathways have been studied in certain prokaryotic and eukaryotic microorganisms. FADH has been found in methylotrophic bacteria, as well as in mammals, plants, and yeasts, where it plays a general role in formaldehyde detoxification and antioxidation (Vorholt 2002). In the present study, fungal FADH and FDH activities were induced by $300 \mathrm{mg} \mathrm{l}^{-1}$ formaldehyde and the enzyme activities were also change over time. The two enzymes were gradually induced and accumulated at the first $24 \mathrm{~h}$. At this point, the strain HUA had the strongest formaldehyde degradation (data not shown), and formaldehyde concentration was reduced rapidly. After $48 \mathrm{~h}$, the formaldehyde was completely consumed, the
FADH and FDH accumulated in strain HUA gradually restored to the initial level. The results indicate that there was a connection between formaldehyde degradation curve, fungal growth curves, and enzyme activities. Achkor et al. (2003) reported that transgenic Arabidopsis overexpressing $A t \mathrm{FADH}$ show a $25 \%$ increase in the detoxification rate compared with the wild-type plants. Recently, FADH genes from Arabidopsis thaliana, golden pothos, and rice were isolated and characterized (Tada and Kidu 2011). Studies on gene cloning of this fungus were in progress to elucidate the gene regulation of formaldehyde metabolism. In addition, when glutathione or NAD was not added in reaction solution, the FADH activity could not be measured. This result clearly showed that formaldehyde dehydrogenase in strain HUA requires glutathione and NAD for activity, which is the same as Candida boidinii (Schutte et al. 1976). It indicates that FADH is one of the key enzymes in formaldehyde metabolism of strain HUA, and the strain HUA has potential applications for contaminated water treatment.

\section{Conclusion}

In this study, a formaldehyde-resistant fungal strain HUA was identified as a member of A. sydowii. The optimal temperature, $\mathrm{pH}$, and carbon source conditions of culture preparation were investigated, and formaldehyde degradation characteristics were determined. The formaldehyde dehydrogenase could play an important role in metabolic formaldehyde process in strain HUA. From the above results, it can be concluded that $A$. sydowii HUA can degrade formaldehyde efficiently, and it could be successfully used for the treatment of industrial wastewater containing formaldehyde. Further experiment should be studied in natural condition to ascertain the exact formaldehyde degradation capacity.

Acknowledgments This study was supported by the Science Foundation for Distinguished Young Scholars of Heilongjiang Province, China (JC201109), the Graduate Innovation Fund of Heilongjiang Province (YJSCX2012-149HLJ), and Aid program for Science and Technology Innovative Research Team in Higher Educational Institutions of Heilongjiang Province (2010TD10) and Harbin Normal University (KJTD2011-2).

\section{References}

Achkor H, Díaz M, Fernández MR, Biosca JA, Parés X, Martínez MC (2003) Enhanced formaldehyde detoxification by overexpression of glutathione-dependent formaldehyde dehydrogenase from Arabidopsis. Plant Physiol 132:2248-2255 
Arutchelvan V, Kanakasabai V, Nagarajan S, Muralikrishnan V (2005) Isolation and identification of novel high strength phenol degrading bacterial strains from phenol-formaldehyde resin manufacturing industrial wastewater. J Hazard Mater 127:238-243

Ashraf MA, Maah MJ, Yusoff I (2011) Heavy metals accumulation in plants growing in ex tin mining catchment. Int $\mathrm{J}$ Environ Sci Technol 8:401-416

Bhakta J, Munekage Y, Ohnishi K, Jana B (2012) Isolation and identification of cadmium- and lead-resistant lactic acid bacteria for application as metal removing probiotic. Int $\mathbf{J}$ Environ Sci Technol 9:433-440

Bradford M (1976) A rapid and sensitive method for the quantitation of microgram quantities of protein utilizing the principle of protein-dye binding. Anal Biochem 72:248-254

Das SK, Das AR, Guha AK (2007) A study on the adsorption mechanism of mercury on Aspergillus versicolor biomass. Environ Sci Technol 41:8281-8287

Di Maiuta N, Hubschmid S, Giuliani N, Schwarzentruber P, Dow CS (2009) Microbial degradation of formaldehyde in white mineral dispersions preserved with formaldehyde-releasing biocides. Int Biodeter Biodegr 63:769-777

Glass NL, Donaldson GC (1995) Development of primer sets designed for use with the PCR to amplify conserved genes from filamentous ascomycetes. Appl Environ Microbiol 61:1323-1330

Hanson AD, Roje S (2001) One-carbon metabolism in higher plants. Ann Rev Plant Physiol Plant Mol Biol 52:119-137

Hasan H (1999) Fungal utilization of organophosphate pesticides and their degradation by Aspergillus flavus and A. sydowii in soil. Folia Microbiol 44:77-84

Hidalgo A, Lopategi A, Prieto M, Serra J, Llama M (2002) Formaldehyde removal in synthetic and industrial wastewater by Rhodococcus erythropolis UPV-1. Appl Microbiol Biotechnol 58:260-264

IARC (2006) Formaldehyde, 2-Butoxyethanol, and 1-tert-Butoxy-2Propanol. International Agency for Research on Cancer, Lyon

Kanmani P, Aravind J, Preston D (2012) Remediation of chromium contaminants using bacteria. Int $\mathrm{J}$ Environ Sci Technol 9:183-193

Kondo T, Morikawa Y, Hayashi N, Kitamoto N (2002) Purification and characterization of formate oxidase from a formaldehyderesistant fungus. FEMS Microbiol Lett 214:137-142

Kondo T, Morikawa Y, Hayashi N (2008) Purification and characterization of alcohol oxidase from Paecilomyces variotii isolated as a formaldehyde-resistant fungus. Appl Microbiol Biotechnol 77:995-1002

Mani D, Kumar C (2013) Biotechnological advances in bioremediation of heavy metals contaminated ecosystems: an overview with special reference to phytoremediation. Int J Environ Sci Technol 10:1-30

Martins M, Mouad A, Boschini L, Regali Seleghim M, Sette L, Meleiro Porto A (2011) Marine fungi Aspergillus sydowi and Trichoderma sp. catalyze the hydrolysis of benzyl glycidyl ether. Mar Biotechnol 13:314-320

Merk O, Speit G (1998) Significance of formaldehyde-induced DNAprotein crosslinks for mutagenesis. Environ Mol Mutagen 32:260-268

Metz B, Kersten GFA, Hoogerhout P, Brugghe HF, Timmermans HAM, de Jong A, Meiring H, Hove JT, Hennink WE, Crommelin DJA, Jiskoot W (2004) Identification of formaldehyde-induced modifications in proteins. J Biol Chem 279:6235-6243

More TT, Yan S, Tyagi RD, Surampalli RY (2010) Potential use of filamentous fungi for wastewater sludge treatment. Bioresour Technol 101:7691-7700
Moussavi G, Heidarizad M (2010) Biodegradation of mixture of phenol and formaldehyde in wastewater using a single-basin MSCR process. J Biotechnol 150:240-245

Nair S, Sindhu R, Shashidhar S (2008) Purification and biochemical characterization of two xylanases from Aspergillus sydowii SBS 45. Appl Biochem Biotech 149:229-243

Nash T (1953) The colorimetric estimation of formaldehyde by means of the Hantzsch reaction. Biochem J 55:416-421

Rocha L, Ferreira H, Pimenta E, Berlinck R, Rezende M, Landgraf M, Seleghim M, Sette L, Porto A (2010) Biotransformation of $\alpha$ bromoacetophenones by the marine fungus Aspergillus sydowii. Mar Biotechnol 12:552-557

Saitou N, Nei M (1987) The neighbor-joining method: a new method for reconstructing phylogenetic trees. Mol Biol Evol 4:406-425

Sawada A, Ikeda R, Tamiya E, Yoshida T, Oyabu T, Nanto H (2006) A novel formaldehyde-degrading fungus, Trichoderma virens: isolation and some properties. IEICE Trans Electron 89:17861791

Schutte H, Flossdorf J, Sahm H, Kula M-R (1976) Purification and properties of formaldehyde dehydrogenase and formate dehydrogenase from Candida boidinii. Eur $\mathrm{J}$ Biochem 62:151-160

Solomon MJ, Varshavsky A (1985) Formaldehyde-mediated DNAprotein crosslinking: a probe for in vivo chromatin structures. PNAS 82:6470-6474

Srivastava S, Thakur I (2006) Biosorption potency of Aspergillus niger for removal of chromium (VI). Curr Microbiol 53:232-237

Tada Y, Kidu Y (2011) Glutathione-dependent formaldehyde dehydrogenase from golden pothos (Epipremnum aureum) and the production of formaldehyde detoxifying plants. Plant Biotechnol 28:373-378

Tamura K, Dudley J, Nei M, Kumar S (2007) MEGA4: molecular evolutionary genetics analysis (MEGA) software version 4.0. Mol Biol Evol 24:1596-1599

Tang X, Bai Y, Duong A, Smith MT, Li L, Zhang L (2009) Formaldehyde in China: production, consumption, exposure levels, and health effects. Environ Int 35:1210-1224

Taştan BE, Ertuğrul S, Dönmez G (2010) Effective bioremoval of reactive dye and heavy metals by Aspergillus versicolor. Bioresour Technol 101:870-876

Thompson JD, Gibson TJ, Plewniak F, Jeanmougin F, Higgins DG (1997) The CLUSTAL_X windows interface: flexible strategies for multiple sequence alignment aided by quality analysis tools. Nucleic Acids Res 25:4876-4882

Tišler T, Zagorc-Končan J (1997) Comparative assessment of toxicity of phenol, formaldehyde, and industrial wastewater to aquatic organisms. Water Air Soil Poll 97:315-322

Usharani K, Muthukumar M (2013) Optimization of aqueous methylparathion biodegradation by Fusarium sp. in batch scale process using response surface methodology. Int J Environ Sci Technol 10:591-606

Vorholt J (2002) Cofactor-dependent pathways of formaldehyde oxidation in methylotrophic bacteria. Arch Microbiol 178:239-249

Yurimoto H, Kato N, Sakai Y (2005) Assimilation, dissimilation, and detoxification of formaldehyde, a central metabolic intermediate of methylotrophic metabolism. Chem Rec 5:367-375

Yurimoto H, Kato N, Sakai Y (2009) Genomic organization and biochemistry of the ribulose monophosphate pathway and its application in biotechnology. Appl Microbiol Biotechnol $84: 407-416$ 
Zhang D, Yang Y, Castlebury LA, Cerniglia CE (1996) A method for the large scale isolation of high transformation efficiency fungal genomic DNA. FEMS Microbiol Lett 145:261-265
Zhao J, Wang X, Zeng J, Yang G, Shi F, Yan Q (2005) Biodegradation of poly(butylene succinate-co-butylene adipate) by Aspergillus versicolor. Polym Degrad Stab 90:173-179 